\title{
Vagus nerve cross-sectional area in patients with Parkinson's Disease - an ultrasound case-control study
}

\author{
Jacob Horsager ${ }^{1 *}$, Uwe Walter ${ }^{2}$, Tatyana D Fedorova ${ }^{1}$, Katrine B. Andersen ${ }^{1}$, Casper
} Skjærbæk ${ }^{1}$, Karoline Knudsen ${ }^{1}$, Niels Okkels ${ }^{1,3}$, Paul von Weitzel-Mudersbach ${ }^{3}$, Stig Eric Dyrskog $^{4}$, Bo Bergholt ${ }^{5}$, and Per Borghammer ${ }^{1}$

${ }^{1}$ Department of Nuclear Medicine and PET, Aarhus University Hospital, Denmark

${ }^{2}$ Department of Neurology, Rostock University, Germany

${ }^{3}$ Department of Neurology, Aarhus University Hospital, Denmark

${ }^{4}$ Department of Neuro-Intensive Care, Aarhus University Hospital, Denmark

${ }^{5}$ Department of Neurosurgery, Aarhus University Hospital, Denmark

* Corresponding author:

Jacob Horsager

Phone (+0045) 26819204

Email: jacobnls@rm.dk

Department of Nuclear Medicine and PET

Aarhus University Hospital

Palle Juul-Jensens Boulevard 165, J220

8200 Aarhus N, Denmark

Keywords: Parkinson's Disease, vagus nerve, ultrasound, parasympathetic, cross-sectional area.

\section{Conflict of Interest}

None

\section{Funding}

The study was supported by the Lundbeck Foundation [grant number: R190-2014-4183]. The funding source had no role in any part of the study.

\section{Running title}

Vagus nerve ultrasound in Parkinson's disease 
medRxiv preprint doi: https://doi.org/10.1101/2021.02.15.21251731; this version posted February 19, 2021. The copyright holder for this preprint (which was not certified by peer review) is the author/funder, who has granted medRxiv a license to display the preprint in All rights reserved. No reuse allowed without permission.

\begin{abstract}
Background. Vagal parasympathetic neurons are prone to degeneration in Parkinson's disease (PD). High-resolution ultrasound can precisely estimate the cross-sectional area (CSA) of peripheral nerves. Here, we tested the hypothesis that vagus CSA is reduced in PD.

Methods. We included 56 healthy controls (HCs) and 63 patients with PD. Using a high-end ultrasound system equipped with a high-frequency transducer, five images were obtained of each nerve. The hypoechoic neuronal tissue was delineated offline with dedicated software and the CSA extracted.

Results. In the initial PD vs. HC comparison, no statistically significant differences were observed in mean left vagus CSA (HC: $\left.1.97 \mathrm{~mm}^{2}, \mathrm{PD}: 1.89 \mathrm{~mm}^{2}, \mathrm{P}=0.36\right)$ or in mean right vagus CSA (HC: $2.37 \mathrm{~mm}^{2}, \mathrm{PD}: 2.23 \mathrm{~mm}^{2}, \mathrm{P}=0.17$ ). The right vagus CSA was significantly larger than the left vagus CSA in both groups $(P<0.0001)$. Females were overrepresented in the HC group and presented with generally smaller vagus CSAs. Consequently, sex-adjusted CSA was significantly smaller for the right vagus nerve of the PD group $(P=0.041)$, but not for the left. Conclusion. A small but significant reduction in sex-adjusted right vagus CSA was observed in patients with PD. The left vagus CSA was not significantly reduced in patients with PD. Ultrasound may not be a suitable method to detecting vagal axonal loss in individual patients.
\end{abstract}


medRxiv preprint doi: https://doi.org/10.1101/2021.02.15.21251731; this version posted February $19,2021$. The copyright holder for this preprint (which was not certified by peer review) is the author/funder, who has granted medRxiv a license to display the preprint in

All rights reserved. No reuse allowed without permission.

\section{Introduction}

The vagus nerve may play a crucial role in the pathogenesis of Parkinson's disease (PD). It has been hypothesized that $\alpha$-synuclein aggregates form in the enteric nervous system, and spread via the autonomic nervous system to the CNS [1]. In this context, vagal parasympathetic neurons that project to most of the gastrointestinal tract serve as entrance to the dorsal motor nucleus of the vagus (DMV). In support, truncal vagotomy decrease the risk of developing PD $[2,3]$. The DMV and the vagus nerve itself are among the most frequently affected structures in post-mortem PD studies [4-7]. This is accompanied by up to $50 \%$ DMV motor neuron loss in deceased patients [8-10].

Using ${ }^{11} \mathrm{C}$-donepezil PET/CT, we have previously demonstrated decreased gastrointestinal acetylcholinesterase density in patients with PD [11-13]. This is believed to reflect parasympathetic denervation, mainly derived from the vagus nerve. Furthermore, subjects with isolated REM-sleep behavior disorder, the strongest marker of prodromal PD [14], also exhibit decreased gastrointestinal acetylcholinesterase density [15]. Hence, the vagal parasympathetic system is affected years before diagnosis in some patients. Therefore, precise evaluation of vagal degeneration could serve as tool to diagnose PD patients, even during the pre-motor phase.

High-resolution ultrasound is a non-invasive, radiation-free alternative to assess vagal degeneration. The method can precisely measure the caliber of superficial nerves. Six previous studies tested the hypothesis that vagal neuron loss is detectable by ultrasound, but reported conflicting results. Three studies found significant atrophy of both left and right vagus nerves in patients with PD [16-18]. In contrast, three studies reported no difference between patients with PD and healthy controls (HCs) [19-21]. Thus, whether ultrasound can detect vagal neuronal loss in patients with PD remains unresolved.

In the present study we determined the vagus cross-sectional area (CSA) in the largest cohort of PD patients studied so far and compared to HCs. Five images of each nerve were obtained to optimize accuracy and all analyses were performed offline for optimal precision. We compared the vagus CSA with measures of gastrointestinal acetylcholinesterase density (parasympathetic innervation) and retained radiopaque markers (estimate of gastrointestinal transit time) in subgroups. These measures should theoretically be altered in parallel to vagal parasympathetic depletion.

\section{Methods}

\subsection{Study population}

We included 63 early-to-moderate stage PD patients and $56 \mathrm{HCs}$. Participants were enrolled between April 2019 and November 2020 from ongoing studies and one published study [13] at Aarhus University Hospital, Denmark. Demographic and clinical information is listed in 
medRxiv preprint doi: https://doi.org/10.1101/2021.02.15.21251731; this version posted February 19, 2021. The copyright holder for this preprint (which was not certified by peer review) is the author/funder, who has granted medRxiv a license to display the preprint in

All rights reserved. No reuse allowed without permission.

Table 1. All participants provided written informed consent. The study was approved by the Science Ethical Committees of the Central Denmark Region.

Table 1. Demographic and clinical information.

\begin{tabular}{|c|c|c|c|c|c|}
\hline & \multicolumn{2}{|c|}{ HC } & \multicolumn{2}{|c|}{ PD } & P-value \\
\hline Sample size $n$ & \multicolumn{2}{|c|}{56} & \multicolumn{2}{|c|}{63} & \\
\hline $\operatorname{Sex} m / f$ & \multicolumn{2}{|c|}{$26 / 30$} & \multicolumn{2}{|c|}{$43 / 20$} & 0.025 \\
\hline Age & \multicolumn{2}{|c|}{$69.1(8.9)$} & \multicolumn{2}{|c|}{$67.4(7.6)$} & 0.25 \\
\hline Time since diagnosis [months] & \multicolumn{2}{|c|}{ - } & \multicolumn{2}{|c|}{$8(2-85)$} & \\
\hline UPDRS III & \multicolumn{2}{|c|}{ - } & \multicolumn{2}{|c|}{$23(10)$} & \\
\hline H\&Y I/II/III & \multicolumn{2}{|c|}{ - } & \multicolumn{2}{|c|}{$14 / 43 / 6$} & \\
\hline LEDD [mg] & & & \multicolumn{2}{|c|}{$656(404)$} & \\
\hline BMI & \multicolumn{2}{|c|}{$24.9(3.7)$} & \multicolumn{2}{|c|}{$26.0(4.1)$} & 0.14 \\
\hline Left vagus CSA $\left[\mathrm{mm}^{2}\right]$ & \multicolumn{2}{|c|}{$1.97(0.48)$} & \multicolumn{2}{|c|}{$1.89(0.48)$} & 0.36 \\
\hline Right vagus CSA $\left[\mathrm{mm}^{2}\right]$ & \multicolumn{2}{|c|}{$2.37(0.57)$} & \multicolumn{2}{|c|}{$2.23(0.55)$} & 0.17 \\
\hline \multirow[t]{2}{*}{ Vagus CSA-symmetry index } & \multicolumn{2}{|c|}{1.17 (1.09-1.39) } & \multicolumn{2}{|c|}{1.19 (1.01-1.37) } & 0.69 \\
\hline & Females & Males & Females & Males & \\
\hline Left vagus CSA [mm²] & $1.86(0.42)$ & $2.09(0.52)$ & $1.81(0.43)$ & $1.92(0.50)$ & - \\
\hline Right vagus CSA [mm²] & $2.23(0.47)$ & $2.54(0.63)$ & $2.01(0.42)$ & $2.33(0.58)$ & - \\
\hline
\end{tabular}

\subsection{Vagus nerve ultrasound}

All images were obtained with a high-end ultrasound system (Philips EPIQ 7, Andover, MA, USA) equipped with a linear array 12.0-MHz transducer (L12-3, Phillips, Bothell, VA, USA). Participants were examined in the supine position by the same investigator $(\mathrm{JH})$, who was not blinded to clinical status at ultrasound examination. The vagus nerve was identified midcervically at the level of the thyroid cartilage. On approximately the same location (within a few centimeters), five individual images were obtained bilaterally, i.e. ten images of each participant. All images were exported to offline analysis. In PMOD 4.0 (PMOD, Zürich, Switzerland), the color scale of each image was adjusted to the maximum intensity of the vagus nerve rim. This was performed to ensure optimal contrast between hypoechoic neuronal tissue and the hyperechoic epineurium. Next, the inner border of the hyperechoic epineurium was delineated and CSA was extracted in $\mathrm{mm}^{2}$ with two decimals (Figure 1). Of the five images of each nerve, the largest and smallest CSA were discarded to prevent influence of potential outliers and the average of the three middle values was used for statistical analyses. All offline image analyses were performed blinded to clinical status. 


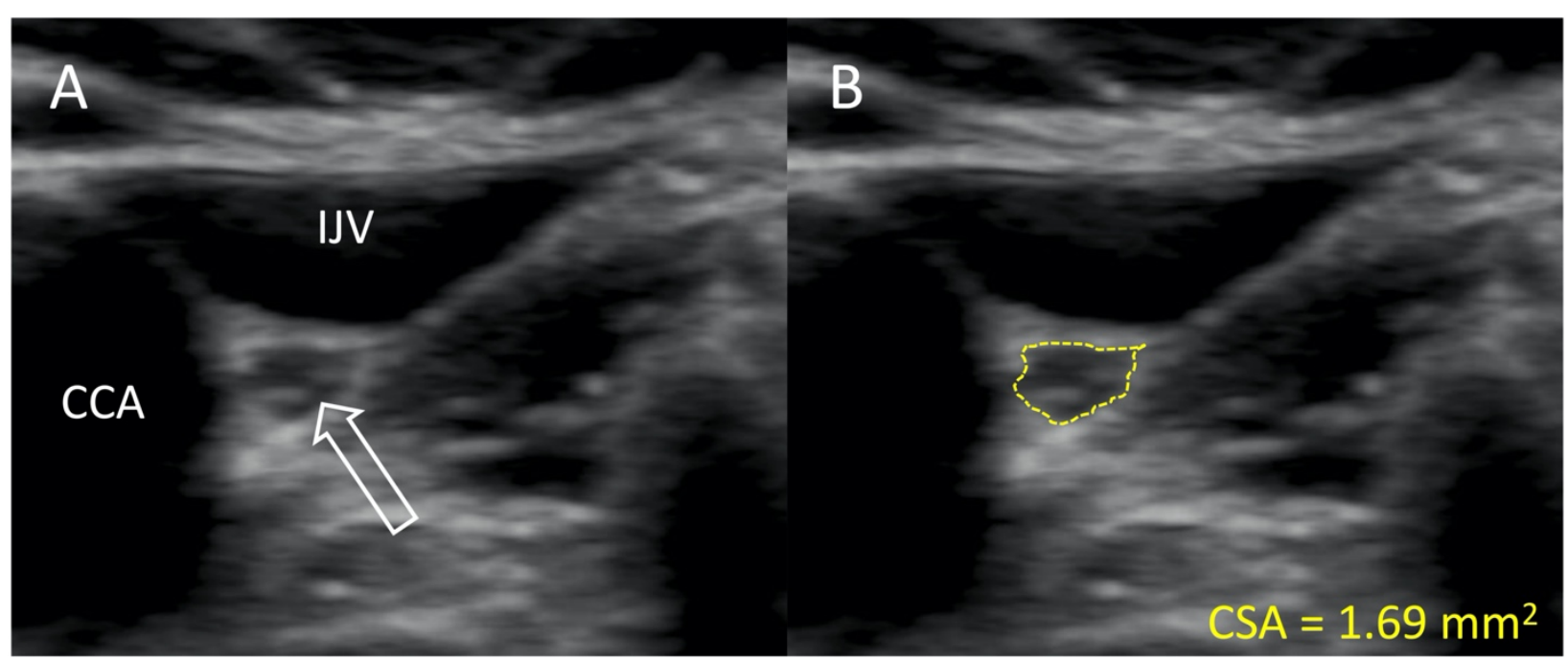

Figure 1. Representative ultrasound image of the vagus nerve. A: The vagus nerve (white arrow) of a patient with PD. B: Delineation of the same vagus nerve following the hyperechoic epineurium. IJV = internal jugular vein, $C C A=$ common carotid artery, $C S A=$ cross-sectional area.

\subsection{Other measurements}

Radiopaque marker ( $R O M)$ data was available for 74 subjects ( $P D=53, H C=21$ ) from two ongoing studies and one published study [13]. In short, ten ROMs were ingested every morning, six days prior to an abdominal CT scan. The number of retained ROMs estimates the colonic transit time. Colonic acetylcholinesterase density (measure of parasympathetic innervation) assessed by ${ }^{11} \mathrm{C}$-donepezil PET/CT, was available in 41 patients with PD [13]. These objective measures of gastrointestinal function and innervation was used to correlate with vagus CSA in subgroup analyses.

\subsection{Statistical analyses}

Statistical analyses were performed with Stata 13.1 and GraphPad Prism 7.0. Normality in distribution was assessed by $Q-Q$ plots and histograms. Group differences of sex were investigated using Fisher's exact tests. Group differences of age and BMI were tested with student's $t$-test. Differences between right and left side were assessed with paired $t$-tests. Differences in symmetry index were assessed with Mann-Whitney-U test. Pearson correlation coefficients were calculated to explore correlations between vagus CSA and other variables (age, BMI, time since diagnosis, disease severity defined by Hoehn and Yahr stage (H\&Y), ROM, and colon acetylcholinesterase density measured by ${ }^{11} \mathrm{C}$-donepezil PET). The unmatched composition of our two cohorts regarding sex was addressed with a multiple linear regression model to calculate sex-adjusted differences in CSA. This model was checked by diagnostic plots of residuals. $P$-values $<0.05$ were considered significant. Method precision was ascertained with coefficient of variation (SD/mean) for each nerve using the three middle CSA values. 
medRxiv preprint doi: https://doi.org/10.1101/2021.02.15.21251731; this version posted February 19, 2021. The copyright holder for this preprint (which was not certified by peer review) is the author/funder, who has granted medRxiv a license to display the preprint in perpetuity.

All rights reserved. No reuse allowed without permission.

\section{Results}

Mean vagus nerve CSAs are presented in Table 1, and depicted graphically in Figure 2. There was no significant difference in the crude comparison between patients with PD and HCs. We observed a tendency towards higher CSA in males than females, most pronounced in the right vagus (Table 1). Thus, we used multiple linear regression to determine sex-adjusted CSA of the vagus. First, we applied a model allowing different slopes in each group. We found no significant slope interactions ( $P>0.5)$. Thus, we applied a model with one common slope. Sexadjusted difference in mean left vagus CSA was $0.12 \mathrm{~mm}^{2}\left(95 \% \mathrm{Cl}:-0.06-0.29 \mathrm{~mm}^{2}, \mathrm{P}=0.19\right)$ and right vagus was $0.21 \mathrm{~mm}^{2}\left(95 \% \mathrm{Cl}: 0.01-0.41 \mathrm{~mm}^{2}, \mathrm{P}=0.041\right)$. In this model, female sex was a significant negative predictor of right vagus CSA $(P=0.003)$, but not of the left vagus CSA $(P=0.06)$. No difference in symmetry index was observed $(P=0.69)$.

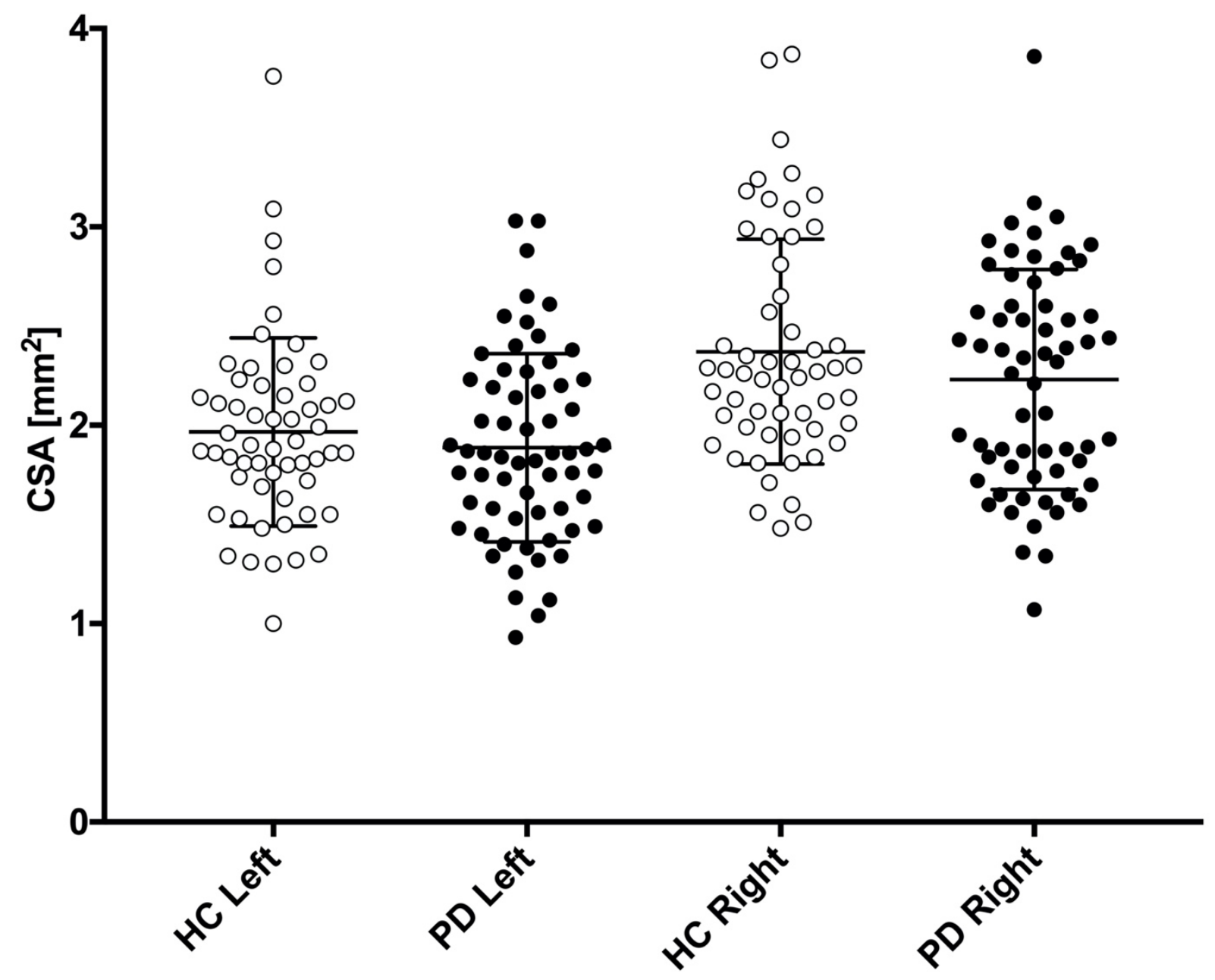

Figure 2. Left and right vagus nerve cross-sectional area (CSA) is presented for patients with Parkinson's disease (PD, black circles) and healthy controls (HC, white circles). Mean and standard deviation is depicted with black error bars.

In the $\mathrm{HC}$ group, mean right vagus CSA was $0.4 \mathrm{~mm}^{2}$ larger than mean left vagus CSA $(95 \% \mathrm{Cl}$ : $0.24-0.57 \mathrm{~mm}^{2}, \mathrm{P}<0.0001$ ). In the PD group, mean right vagus CSA was $0.34 \mathrm{~mm}^{2}$ larger than left vagus CSA ( $\left.95 \% \mathrm{Cl}: 0.20-0.48 \mathrm{~mm}^{2}, \mathrm{P}<0.0001\right)$. Left- and right vagus CSA did not correlate 
medRxiv preprint doi: https://doi.org/10.1101/2021.02.15.21251731; this version posted February 19, 2021. The copyright holder for this preprint (which was not certified by peer review) is the author/funder, who has granted medRxiv a license to display the preprint in All rights reserved. No reuse allowed without permission.

with age, $B M I$, time since diagnosis, disease severity ( $\mathrm{H} \& \mathrm{Y}), \mathrm{ROM}$ (estimate of colonic transit time), or colon acetylcholinesterase density measured by ${ }^{11} \mathrm{C}$-donepezil PET $(\mathrm{P}>0.05)$. Mean coefficient of variation of vagus CSAs was $6.7 \%$.

\section{Discussion}

In the present study we found no difference in vagus nerve CSA between patients with PD and HCs, but female vagus CSA was smaller than male vagus CSA in both groups. One previous report found the opposite pattern; vagus CSA in females were larger than males [22]. More females were included in our $\mathrm{HC}$ group compared to the PD group. Hence, we determined the sex-adjusted differences between patients with PD and HCs, and found a statistically significant reduction of the right vagus CSA $(P=0.041)$ but not of the left vagus CSA $(P=0.19)$.

Although the mean right vagus CSA was significantly reduced in PD, the effects size of $10 \%$ is small. The effect size in other studies, which reported statistically significant CSA reduction, range from approximately 10-30\% [16-18]. Neuronal loss in DMV has been reported to be up to $50 \%$ in post-mortem studies [8-10]. Other nuclei related to the vagus nerve (nucleus ambiguus, solitary nucleus, and spinal trigeminal nucleus) are less affected by $\alpha$-synuclein aggregates [23]. Also, no motor neurons are lost in nucleus ambiguus [9, 24]. The axonal diameter of somato-motor and somato-sensory myelinated fibers is generally much larger than that of autonomic neurons, and must necessarily occupy a substantial fraction of the mid-cervical vagus CSA. Cardiac sympathetic neurons also reside in the vagus nerve and occupy up to $5 \%$ of the CSA $[25,26]$. Cardiac sympathetic neurons are particularly vulnerable in PD and may also contribute to slight vagal atrophy [27]. However, if vagal atrophy is mainly caused by sympathetic and parasympathetic (DMV) axonal loss, the reduction in CSA is probably very small, and could explain why three studies failed to show vagal atrophy in PD [19-21]. Additionally, the vagus nerve shows frequent branching (up to 29\%) [28]. Branched nerves have smaller CSA at the mid-cervical level [28]. Although we have no reasons to believe that branching should differ between patients with PD and $\mathrm{HC}$, it may have contributed to increased data variance.

Time since diagnosis could be another factor explaining some incongruence between studies. In the present study the median duration was short (8 months), as many of the patients were newly diagnosed. The three previous studies that demonstrated significant CSA reduction included patients 5-10 years post diagnosis [16-18]. Thus, the rather small difference demonstrated in the present study might be partly caused by the shorter duration of motor symptoms. However, we found no correlation between vagus CSA and time since diagnosis in the present data, and the three studies that failed to show a significant difference also investigated moderately affected patients, 4-8 years post diagnosis [19-21].

If a biological difference in right vagus CSA truly exists between patients with PD and HCs, two aspects may have enabled us to identify this small difference in the present study; 1 ) our 2-3 
medRxiv preprint doi: https://doi.org/10.1101/2021.02.15.21251731; this version posted February 19, 2021. The copyright holder for this preprint (which was not certified by peer review) is the author/funder, who has granted medRxiv a license to display the preprint in perpetuity.

All rights reserved. No reuse allowed without permission.

times larger PD cohort than previous studies, and 2) offline measurements as advised for optimal precision [29]. However, our study does not support that this method can be applied for meaningful interpretation at the individual level, because the average between-group difference of $0.21 \mathrm{~mm}^{2}$ is hardly discerned, given that the normal vagal CSA ranges from $1 \mathrm{~mm}^{2}$ to nearly $4 \mathrm{~mm}^{2}$ (Figure 2 ).

Right vagus CSA was significantly larger than left vagus CSA as previously reported [16-19, 21, $22,29]$. This also corresponds to the side-to-side difference of the cervical vagus neuronal area defined on post-mortem [30]. Further, the right mid-cervical vagus contains $\sim 20 \%$ more nerve fibers than the left [31]. The mean CSA values were in reasonable agreement with six previous studies that estimated vagus CSA by tracing the epineural rim, as in the present study $[16,18,19,21,22,29]$. Thus, in studies using the tracing method, a reasonable inter-study reproducibility of the vagus CSA seems to exists.

Vagus CSA did not correlate with the number of retained ROM, nor with colon acetylcholinesterase density measured by ${ }^{11} \mathrm{C}$-donepezil PET. If vagus CSA atrophy occurs in parallel to parasympathetic denervation, we would expect these parameters to be correlated. However, not all participants had ROM and ${ }^{11} \mathrm{C}$-donepezil PET data available which could explain the absence of correlation between these parameters.

The precision of the three middle values was evaluated for each nerve by calculating the coefficient of variation. The average coefficient of variation was acceptable (6.7\%). We also calculated the average distance from the three middle values to the mean. The average distance was $4.9 \%$ of the mean, e.g. values defining a CSA of $2 \mathrm{~mm}^{2}$ on average were $0.1 \mathrm{~mm}^{2}$ from the "exact" value. Therefore, we argue that obtaining five ultrasound images of each nerve and using the three middle values to determine the CSA yields precise results.

This study has some limitations. First, the ultrasound investigator was not blinded to clinical status during examination. However, the offline CSA estimation was performed blinded. Second, our two groups were matched on age but not sex, forcing us to do linear adjustment in the comparison analyses.

In conclusion, we found a small but significant reduction in sex-adjusted right vagus CSA in patients with PD. No difference was found in left vagus CSA. Sex was a significant predictor for the right- but not left vagus caliber. This study does not support the use of vagus ultrasound as a diagnostic marker for PD, but there may be applications for the method in a research setting. 
medRxiv preprint doi: https://doi.org/10.1101/2021.02.15.21251731; this version posted February 19, 2021. The copyright holder for this preprint (which was not certified by peer review) is the author/funder, who has granted medRxiv a license to display the preprint in perpetuity.

All rights reserved. No reuse allowed without permission.

\section{References}

1. Hawkes, C.H., K. Del Tredici, and H. Braak, Parkinson's disease: a dual-hit hypothesis. Neuropathol Appl Neurobiol, 2007. 33(6): p. 599-614.

2. Svensson, E., et al., Vagotomy and subsequent risk of Parkinson's disease. Ann Neurol, 2015. 78(4): p. 522-9.

3. Liu, B., et al., Vagotomy and Parkinson disease: A Swedish register-based matchedcohort study. Neurology, 2017. 88(21): p. 1996-2002.

4. Braak, H., et al., Staging of brain pathology related to sporadic Parkinson's disease. Neurobiol Aging, 2003. 24(2): p. 197-211.

5. Beach, T.G., et al., Multi-organ distribution of phosphorylated alpha-synuclein histopathology in subjects with Lewy body disorders. Acta Neuropathol, 2010. 119(6): p. 689-702.

6. Gelpi, E., et al., Multiple organ involvement by alpha-synuclein pathology in Lewy body disorders. Mov Disord, 2014. 29(8): p. 1010-8.

7. Kalaitzakis, M.E., et al., The dorsal motor nucleus of the vagus is not an obligatory trigger site of Parkinson's disease: a critical analysis of alpha-synuclein staging. Neuropathol Appl Neurobiol, 2008. 34(3): p. 284-95.

8. Gai, W.P., et al., Age-related loss of dorsal vagal neurons in Parkinson's disease. Neurology, 1992. 42(11): p. 2106-11.

9. Eadie, M.J., The Pathology of Certain Medullary Nuclei in Parkinsonism. Brain, 1963. 86: p. 781-92.

10. Greene, J.G., Causes and consequences of degeneration of the dorsal motor nucleus of the vagus nerve in Parkinson's disease. Antioxid Redox Signal, 2014. 21(4): p. 64967.

11. Gjerloff, T., et al., Imaging acetylcholinesterase density in peripheral organs in Parkinson's disease with 11C-donepezil PET. Brain, 2015. 138(Pt 3): p. 653-63.

12. Fedorova, T.D., et al., Decreased intestinal acety/cholinesterase in early Parkinson disease: An (11)C-donepezil PET study. Neurology, 2017. 88(8): p. 775-781.

13. Horsager, J., et al., Brain-first versus body-first Parkinson's disease: a multimodal imaging case-control study. Brain, 2020. 143(10): p. 3077-3088.

14. Heinzel, S., et al., Update of the MDS research criteria for prodromal Parkinson's disease. Mov Disord, 2019. 34(10): p. 1464-1470.

15. Knudsen, K., et al., In-vivo staging of pathology in REM sleep behaviour disorder: a multimodality imaging case-control study. Lancet Neurol, 2018. 17(7): p. 618-628.

16. Tsukita, K., et al., The vagus nerve becomes smaller in patients with Parkinson's disease: A preliminary cross-sectional study using ultrasonography. Parkinsonism Relat Disord, 2018. 55: p. 148-149.

17. Walter, U., et al., Atrophy of the Vagus Nerve in Parkinson's Disease Revealed by High-Resolution Ultrasonography. Front Neurol, 2018. 9: p. 805.

18. Pelz, J.O., et al., Axonal Degeneration of the Vagus Nerve in Parkinson's Disease-A High-Resolution Ultrasound Study. Front Neurol, 2018. 9: p. 951.

19. Fedtke, N., O.W. Witte, and T. Prell, Ultrasonography of the Vagus Nerve in Parkinson's Disease. Front Neurol, 2018. 9: p. 525.

20. Laucius, O., et al., Ultrasonography of the Vagus Nerve in the Diagnosis of Parkinson's Disease. Parkinsons Dis, 2020. 2020: p. 2627471.

21. Sijben, L.C.J., et al., The cross-sectional area of the vagus nerve is not reduced in Parkinson's Disease patients. medRxiv, 2020. 
medRxiv preprint doi: https://doi.org/10.1101/2021.02.15.21251731; this version posted February 19, 2021. The copyright holder for this

preprint (which was not certified by peer review) is the author/funder, who has granted medRxiv a license to display the preprint in perpetuity.

All rights reserved. No reuse allowed without permission.

22. Walter, U. and P. Tsiberidou, Differential age-, gender-, and side-dependency of vagus, spinal accessory, and phrenic nerve calibers detected with precise ultrasonography measures. Muscle Nerve, 2019. 59(4): p. 486-491.

23. Del Tredici, K., et al., Where does parkinson disease pathology begin in the brain? J Neuropathol Exp Neurol, 2002. 61(5): p. 413-26.

24. Benarroch, E.E., et al., Involvement of vagal autonomic nuclei in multiple system atrophy and Lewy body disease. Neurology, 2006. 66(3): p. 378-83.

25. Seki, A., et al., Sympathetic nerve fibers in human cervical and thoracic vagus nerves. Heart Rhythm, 2014. 11(8): p. 1411-7.

26. Seki, A., P.S. Chen, and M.C. Fishbein, Reply to the editor-does the cervical vagus contain sympathetic fibers that act on the heart? Heart Rhythm, 2014. 11(10): p. e79-80.

27. Lamotte, G., et al., Cardioselective peripheral noradrenergic deficiency in Lewy body synucleinopathies. Ann Clin Transl Neurol, 2020.

28. Hammer, N., et al., Human vagus nerve branching in the cervical region. PLoS One, 2015. 10(2): p. e0118006.

29. Pelz, J.O., et al., Sonographic evaluation of the vagus nerves: Protocol, reference values, and side-to-side differences. Muscle Nerve, 2018. 57(5): p. 766-771.

30. Verlinden, T.J., et al., Morphology of the human cervical vagus nerve: implications for vagus nerve stimulation treatment. Acta Neurol Scand, 2016. 133(3): p. 173-82.

31. Hoffman, H.H. and H.N. Schnitzlein, The numbers of nerve fibers in the vagus nerve of man. Anat Rec, 1961. 139: p. 429-35. 